\title{
Learning to Fly: Development and Design of a Micro-Credentialing System for an Educator Preparation Program in the Absence of a Required Educational Technology Course
}

\author{
Jon M. Clausen ${ }^{1,2}$ (ID
}

Accepted: 30 September 2021 / Published online: 14 October 2021

(c) Association for Educational Communications \& Technology 2021

\begin{abstract}
Technology integration within instructional practices is an essential element in the preparation of teachers. However, expectations that a single course or hopes that technology infusion will spontaneously occur are not enough to prepare teacher candidates to integrate technology in meaningful ways. In the absence of a required educational technology course for all initial licensure candidates, an educator preparation program in the Midwest sought creative solutions to meet accreditation and clinical placement expectations regarding candidate preparation to integrate technology. This report from the field discusses the iterative process to develop a comprehensive micro-credentialing system aligned with the ISTE standards for educators. The micro-credentials provide candidates opportunities to apply and model technology use within courses and throughout their program. Feedback from stakeholders indicated both possibilities and potential challenges in the adoption of the system. This feedback has led to further development of the micro-credentialing system.
\end{abstract}

Keywords Micro-credentials · Badges · Technology infusion · Technology integration · Teacher education

\section{Introduction}

Preparing teachers to think critically about technology use and integration within teaching and learning contexts continues to be highlighted by policymakers, teacher education accreditation agencies, and professional organizations (e.g., Council of Chief State School Officers, 2011, Council for the Accreditation of Educator Preparation (CAEP), 2016, 2021; International Society for Technology in Education (ISTE), 2017, U.S. Department of Education Office of Educational Technology, 2016, 2017). Specifically, the U.S. Department of Education, Office of Educational Technology (2016) convened the Educational Technology in Teacher Education Innovation Summit. The summit challenged teacher preparation programs to enact four guiding principles to prepare

Jon M. Clausen

jmclaus@bsu.edu

1 Ball State University, 2000 W. University Ave, Muncie, IN 47306, USA

2 Secondary Education and Educational Technology, Teachers College, Ball State University, 881-959 N. McKinley Ave, Muncie, IN 47303, USA teacher education candidates to use technology effectively for teaching and learning. These guiding principles include:

- Focus on the active use of technology to enable learning and teaching through creation, production, and problemsolving.

- Build sustainable, program-wide systems of professional learning for higher education instructors to strengthen and continually refresh their capacity to use technological tools to enable transformative learning and teaching.

- Ensure pre-service teachers' experiences with educational technology are program-deep and program-wide, rather than one-off courses separate from their methods courses.

- Align efforts with research-based standards, frameworks, and credentials recognized across the field. (p.9)

As teacher education candidates enter the workforce, they are expected to integrate technology throughout their instruction. This expectation signifies that teacher education programs should prepare teacher candidates to accomplish such a feat. "The ultimate goal for teacher preparation programs should be a technology infused program that provides a more concerted effort to address teaching with 
technology throughout the curriculum" (Foulger et al., 2017 , p. 416). Unfortunately, there continues to be evidence that this goal remains elusive. A survey developed by the Organization for Economic Co-operation and Development (OECD) (2019) found that 63\% of U.S. respondents reported technology use as part of their preparation program. Only $45 \%$ claimed they were well or very well prepared to use technology for teaching. In another study focused on teacher educators' perspectives on technology infusion, researchers found troubling signs that key structures within teacher education programs lacked support to make technology infusion possible (Clausen et al., 2021). For teacher education to meet the challenge of preparing candidates to enter the workforce ready to integrate technology, they must develop creative solutions to overcome barriers and infuse technology throughout their programs.

In this report from the field, I describe the iterative process and initial phases of how an educator preparation program (EPP) is attempting to demonstrate program-deep and program-wide technology infusion through the development of a comprehensive microcredentialing program. The micro-credentialing program addresses the ISTE standards for educators (2017) and infuses technology use throughout the undergraduate teacher preparation program. The micro-credentials are designed to engage teacher education candidates in a process that allows them to apply and model technology use within courses throughout the EPP. I also report on initial feedback from various stakeholders about the micro-credentialing program. Perspectives from teacher education candidates, faculty, and administration provided insights into promising implications of adopting micro-credentials into the EPP. Stakeholder perspectives also highlighted potential challenges in the adoption of micro-credentials.

\section{Introduction of Micro-credentials}

Micro-credentials have been used as vehicles for, and evidence of, professional learning within a wide range of professional settings. Adult learners are acquiring microcredentials to demonstrate competencies in fields such as computer networking and infrastructure (IBM, n.d.), health care (American Association of Critical-Care Nurses, 2020), construction management (Construction Management Association of America, 2021), education (Digital Promise, n.d.), among others. Micro-credentials are used to meet evolving skill sets and changing professional demands. Employers are also using them to encourage continued professional development and to address emerging issues in the workplace (Guathier, 2020).

\section{Defining Terms}

Learners earning recognition after completing a set of requirements that demonstrate knowledge, skills, or competencies can be traced back to badges earned in scouting. The concept of open badges was introduced in 2012 by Mozilla to recognize different types of learning experiences and communicate them to others (Mozilla Foundation, Peer 2 Peer University,, \& MacArthur Foundation, 2012). Unlike a traditional course grade or certificate, open badges utilize digital technologies making them portable and shareable. "A digital badge is a representation of an accomplishment, interest, or affiliation that is visual, available online, and contains metadata including links that help explain the context, meaning, process, and result of an activity" (Gibson et al., 2015, p. 405). The embedded metadata also provides the earner with the opportunity to share the specific criteria met and artifacts they created with others (Young et al., 2019). Individuals can then store their accumulated digital badges into a digital backpack and tailor collections of credentials into different collections for specific audiences. Various organizations, including professional organizations, nonprofit and for-profit organizations, companies, and educational institutions, issue micro-credentials. Issuers develop badges to align with professional standards, skills, or other criteria. Issuers set up badge constellation systems where stacked credentials create learning pathways for earners to complete (Skipper, 2018). These pathways can lead to certifications or specializations the earner wants to emphasize that highlight a specific skill set or expertise.

The terms micro-credential and badge are frequently used interchangeably. However, there are important differences that professional learning organizations should take into account when considering the development of a micro-credentialing or badging program. Elliott et al. (2014) distinguish micro-credentials as, "only awarded on the acquisition of specific knowledge or demonstrated competency of an identified skill. They are then validated by recognized professional bodies or educational institutions" (p. 704). A key difference is the validation of the micro-credential by a professional organization or institution. Criteria for earning micro-credentials may include the construction of an artifact requiring a specific skill. Alternatively, "digital badges are awarded to indicate progress being made or activities undertaken...The main purpose is to encourage learner ongoing engagement which can be seen to be motivational" (Elliott et al., 2014, p. 704). These may include participation in, or completion of, an activity or course. 


\section{Micro-Credentials in Higher Education}

Several scholars have advocated that micro-credentialing systems can benefit the institution or program utilizing them. Ahn et al. (2014) argue that a college degree cannot capture all the knowledge, skills, and accomplishments that a graduate has. Micro-credentialing can provide detailed information on a larger number of learning achievements than is possible on a course level. When designed in a specific manner, micro-credentials "strengthen traditional degree programs, support competency-based programs, and link badge earners to potential employers and professional organizations" (Carey \& Stefaniak, 2018, p. 1212). Micro-credentials are helpful in higher education to capture learning that might otherwise go unrecognized through formal academic procedures (Devedzic \& Jovanovic, 2015). Higher education institutions are exploring micro-credentials in both course-based and program-based settings (Stefaniak \& Carey, 2019). For example, West and Randall (2016) reimagined an undergraduate web programming course that allowed students to use open badges from other organizations as evidence for course competencies. In another example, Reid et al. (2015) adopted digital badges with undergraduate composition courses by connecting badge requirements to course outcomes.

\section{Micro-Credentials for Assessment of Learning}

The use of micro-credentials provides multiple forms of assessment, including instructor, peer, and self-assessment (Gibson et al., 2016). Different systems and platforms for micro-credentialing can assess, document, and align learning outcomes with competencies (Newby et al., 2016; Reid et al., 2015; Wilson et al., 2016). These systems may be private (e.g., Purdue Passport) or open (e.g., Badgr Backpack). However, effective adoption of micro-credential systems also come with several challenges, including technical difficulties, lack of support and buy-in, need for training, absence of program vision, ensuring sustainability for programs, and failure to align badge programs with university mission (Carey \& Stefaniak, 2018; Wilson et al., 2016). Stefaniak and Carey (2019) warn, "Poorly designed badges which are awarded when competencies are not completely met are a threat to badge validity within the badge system and in the wider badge community" (p. 4). Morris et al. (2019) found no significant improvements in student learning for university students in low- and high-stakes contexts where badges were used. In identifying limitations to their study, Morris et al. (2019) suggest that "implementing badges effectively in education requires considerable effort on the part of instructors and students” (p. 598). They continue, “... implementing badges in a course may be fairly simple but implementing badges in a way that improves learning might be quite difficult and should not be limited to assessment performance (i.e., quizzes and post-tests) alone" (p. 598).

\section{Micro-Credentials in Teacher Education}

For teacher education programs, micro-credentialing systems are opportunities to demonstrate candidate professional learning and growth. Micro-credentials allow individuals to display mastery of knowledge or ability in a particular setting or subject (Randall et al., 2013). Also, they enable learning to take place outside of classrooms or usual domains of education (Carey \& Stefaniak, 2018). As Gamrat et al. (2014) state, "Badges can act like a portfolio, documenting workplace learning and artifacts that can be shared with fellow colleagues and supervisors, or as repositories of content or reflection" (p. 1137). Others also suggest that micro-credentialing can support faculty technology competencies (Foulger et al., 2017). Watson, $\mathrm{Yu}$, Alamri, and Watson (2020) found that digital badges were overwhelmingly ranked as the most impactful instructional component throughout the course by students. Digital badges promote increased self-efficacy through formative feedback and the ability to resubmit evidence in cases of inadequate performance. Earned badges also support goal setting as they represent learner accomplishments (Cheng et al., 2018).

Existing examples of micro-credential use within teacher education have been primarily in programs with required educational technology courses for teacher education candidates and specific courses that emphasize technology use (Newby et al., 2016; Newby \& Cheng, 2020; Randall et al., 2013; Watson et al., 2020). These studies have focused on self-regulation, attitude change, motivation, and technology knowledge and skills. Much less is known about how teacher education programs use micro-credentials to document how they prepare candidates to use technology throughout the preparation experience.

Micro-credentialing systems include many benefits for teacher education programs to address expectations from policymakers and accreditation agencies. They also present intriguing ways for programs to infuse technology throughout the experiences of teacher candidates. Examples of how micro-credentialing could be embedded within educator preparation to support technology infusion include:

- Programs that do not have a required foundational course in educational technology.

- Programs with a required educational technology course seeking additional ways to document technology infusion throughout the curriculum.

- Programs that need to address changing requirements and demands from state departments of education or accreditation organizations. 
- Programs that want to provide candidates opportunities to demonstrate, document, and share their ability to integrate technology for teaching and learning.

West et al. (2020) identify several reasons for the need for additional research and case studies that reflect on the development and implementation of micro-credentials. This report from the field addresses this need and describes how an EPP is developing a micro-credentials program within teacher education.

\section{Educator Preparation Program Context}

The university has an extensive educator preparation program with an undergraduate enrollment of 1200 students and 27 licensure areas. Graduates express confidence in their technology use in a post-graduation survey administered by the EPP. However, the EPP does not have a required educational technology course for all teacher education candidates and currently does not monitor how they use technology throughout their preparation program. A foundational educational technology course would provide candidates with baseline knowledge about concepts, frameworks, and pedagogical practices that support learning (Wilson et al., 2020). Instead, candidates rely on their own prior PK12 educational experiences, personal exploration, or they happen to have a faculty member that supports and models technology integration. The EPP does offer educational technology coursework, a minor in educational technology, a computer education license addition, and an educational technology concentration to undergraduates, but these courses and programs are electives.

In recent years, program leadership has recognized that additional steps were needed to prepare teacher candidates for schools that have adopted a range of technologies (e.g., learning management systems and one-to-one devices). This increase in technology adoption by area schools has established hiring expectations that candidates will have the knowledge and experience to integrate technology within their instructional practices (Young et al., 2019). The accreditation body used by the EPP also identified technology as a "cross-cutting theme," emphasizing the importance of technology integration throughout the educator preparation program (CAEP, 2016).

These factors incentivized EPP leadership to examine how the program supported faculty and prepared teacher candidates to use technology for teaching and learning. Leadership recognized this as an area needing attention. However, the prospect of adding an additional course to the 120 credit hours already required of candidates was not an option. An educational technology faculty member had been investigating the development of micro-credentials within his educational technology courses and suggested microcredentials may be a way to address the need facing the EPP. A micro-credential system could create an opportunity for the EPP to gather data and report results for accreditation. It would help EPP leadership tackle the challenge of technology integration, use, and modeling by candidates and faculty within the program. It would also demonstrate that program-deep and program-wide technology infusion was taking place throughout the EPP. The next section will provide information about the development and design of the micro-credentialing system.

\section{Digital Fliers Professional Learning Program Design and Development}

The Digital Fliers Professional Learning Program (PLP) design and construction have been developmental and iterative. The process began as part of an immersive learning project with students enrolled in an educational technology course. The challenge was to create professional development activities for area teachers and a school district that had recently adopted a new learning management system. The initial iteration of the PLP was created with a physical outcome in mind (the creation of professional development activities for classroom teachers). Review of the work by teachers, administrators, faculty, and community members expressed appreciation, but also a common question, "Can you make them digital?" At approximately the same time, the faculty member had attended the National Technology Leadership Summit (NTLS). He participated in a research strand focusing on micro-credential use within education. With the information and knowledge gained during NTLS, the faculty member continued the project the next semester. He worked with another group of students to refine and expand activities creating micro-credentials. Students also explored digital platforms for hosting micro-credentials. In the current iteration, the faculty member worked with a student to edit PLP activities and construct the micro-credentials within the Badge List hosting service (https://www. badgelist.com/).

To design and refine each of the micro-credentials, student designers applied various levels of Bloom's taxonomy and considered activities they would enjoy doing as they addressed the standard indicators. They also evaluated existing assignments from their own experiences within the EPP and reimagined how those assignments could be constructed to incorporate elements from the ISTE standards for educators (2017). The student designers began asking how they might embed the micro-credentials within the teacher education program or how they could engage faculty members about the possibility of incorporating them into existing courses. 

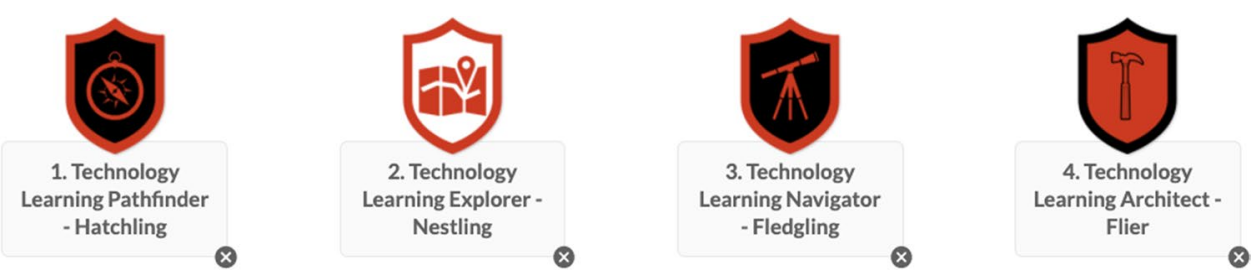

Fig. 1 Levels of Digital Fliers Micro-credentials for ISTE Educator Learner Standard. EDTECBSU - Learner Micro-credentials. These represent examples of the four levels of micro-credentials aligned with the ISTE learner standard

The approach taken by student designers was to engage both candidates and faculty in a change process that would identify areas within the existing curriculum to be improved. They would also provide new ways candidates could demonstrate their knowledge. The approach was not to develop a system for course credit or to meet degree requirements. Instead, in the absence of a required educational technology course, the micro-credentials would be used to demonstrate knowledge, skills, and competencies about technology integration throughout the EPP. Using the ISTE standards for educators (2017) demonstrated that the micro-credentials aligned to standards recognized across the field of educational technology and teacher education.

Each of the seven ISTE standards for educators has several indicators that detail additional criteria that address the standard. Designers created their badging constellation around the standards and the indicators. For each standard, there are four micro-credentials to be completed by earners at different times within the EPP. For example, Fig. 1 shows the four EDTECBSU - Learner micro-credentials.

At the introductory level of the standard, candidates complete tasks at the "hatchling" stage. These initial tasks are basic and designed to introduce earners to concepts or resources. Tasks and activities become more complex at each stage (hatchling, nestling, fledgling, \& flier) while providing candidates with diverse ways to demonstrate their knowledge and skills. For example, candidates who earn the EdTecBSU - Learner micro-credentials (Appendix) begin at the "hatchling" level by identifying three professional organizations related to their content, grade level, technology, or other interest area and submitting the URLs of those organizations with a brief description of each. By the time earners reach the "flier" level, they have completed a five-week professional learning plan and submitted evidence of their participation in several professional learning activities to expand their knowledge of teaching and learning.

The design of the micro-credentialing system aligns with EPP goals and objectives of preparing educators to enter the classroom ready to incorporate technology for teaching and learning. Developing a micro-credentialing system with an open badging framework allows candidates to carry their achievements beyond the course. Candidates can use the open badging framework to demonstrate their knowledge and competencies to other faculty and potential employers. It also allows the EPP to gather information for accreditation reports.

As student designers of the PLP examined open badging platforms, they reviewed platforms that would easily connect to the university's learning management system and other systems teacher candidates may encounter in the future. They selected Badge List (2020) because of its ease of use and ability to connect to other systems. Its features are easy to use and have a standard layout for each micro-credential. These features allow for a systematic approach to the micro-credentials, decreasing confusion and promoting the system's usability. Additionally, Badge List credentials are compatible with the Open Badge standard, can connect to the Badgr Backpack (2020) and the Open Badges project (2020). The Badgr Backpack (2020) is a common location to collect micro-credentials and allows other micro-credentials outside the Digital Fliers PLP to be easily displayed. The Badgr Backpack creates an opportunity for teacher education candidates to show a diverse array of knowledge and skills within one location.

\section{Introduction of Digital Fliers to Stakeholders within the Educator Preparation Program}

Educational technology faculty and student designers sought feedback from different stakeholders who could assist in developing and refining the micro-credentials within the Digital Fliers PLP. Introductions to the micro-credentials focused on three groups of stakeholders: teacher education candidates, elementary education faculty, and college leadership and accreditation personnel. The feedback from these stakeholders was informal, and designers did not collect data from the participants. The designers hoped information gained would inform continued iterations and development of the Digital Fliers PLP and ease the adoption of the micro-credentials within the larger professional education campus community. 


\section{Introduction to Candidates}

Students enrolled in an undergraduate educational technology course on learning and teaching with emerging technologies were asked to review the Digital Fliers program and provide feedback about where they might place the various micro-credentials within courses or different places within their preparation program. The class of approximately twenty students included candidates from multiple content areas (elementary education, social studies education, math education, English education, and family consumer science). The class had been exploring concepts like gamification, personalized learning, and achievement goal theory. They had also completed several Apple Teacher (2020) badges to learn more about how micro-credentialing supports learning. They would now provide feedback about a micro-credentialing system that could support their development and address needs within their preparation program.

At the start of the process, students were provided access to the Badge List platform and given time to review the micro-credentials. From there, they examined the criteria for earning the credentials and reflected on where the credentials might fit within courses or the EPP. The next step was for the candidates to collaborate to share their thoughts and recommendations with peers in the class. The groups then synthesized their recommendations and shared them with the whole class. Responses from the student groups identified several places within the EPP where students thought there would be clear connections to existing course content, concepts, and assessments. Credential placement within the EPP may have included adopting all four credentials within a particular course or a credential set spread out among various courses. They also had difficulty identifying where some credentials might fit because activities involved in earning the credentials took place only in elective educational technology courses.

Candidates saw clear connections with how required courses in educational psychology could easily adopt credentials aligned with the ISTE analyst standard. These courses discuss formative and summative assessment, require candidates to create assessments, and work with data. Another example involved the set of credentials aligned with the ISTE learner standard. Candidates suggested that these credentials would be appropriate in the introduction to education courses. These credentials emphasize teachers as lifelong learners and require credential earners to investigate professional organizations, participate in professional development activities, and complete their own five-week professional learning plan.

Candidates expressed that other micro-credentials should be distributed across the EPP within methods courses, practicum, or student teaching. These included credentials aligned with the ISTE collaborator, facilitator, and designer standards. These credentials included developing and implementing lesson plans, developing online modules, or recording and reflecting on their instruction. Some candidates also identified certain credentials for specific courses, including special education and multicultural education. These credentials specifically focused on differentiation, equitable access to technology, and cultural competency.

Candidates had difficulty identifying where to locate credentials aligned with the ISTE leader and citizen standards. Candidates based their comments on their existing knowledge and experiences. They expressed that they did not have experiences exploring these topics within the EPP. Although candidates found that some of the leader credential set applied elsewhere, they indicated that the only time they had discussed issues of digital citizenship and visions about technology use for learning and teaching were in educational technology courses.

Additional feedback from students was encouraging. The candidates appreciated that they would potentially have control of directing their learning by working on different micro-credentials. They expressed excitement about the possibility of submitting evidence of their competencies in a variety of formats, including images, audio recordings, infographics, and video, compared to the more traditional wordprocessed papers or PowerPoint presentations. Finally, they were excited about the prospects of sharing their collected micro-credentials with an external audience. Being able to export their achievements and tailor the collection of microcredentials into a portfolio to fit specific job criteria created a new way for candidates to set themselves apart from other applicants seeking the same position.

When asked about challenges to implementing the Digital Fliers micro-credentialing system within the EPP, candidates expressed concern that faculty across the EPP might not see the benefits of using micro-credentials. Candidates shared experiences of faculty opposed to the adoption and use of technology by students or who were not flexible in how students demonstrated their knowledge and competencies in specific subject areas. They also indicated that faculty would see micro-credentials as an add-on and just another thing leadership was asking them to do. The candidates eventually suggested a way to overcome these challenges would be to identify faculty who might pilot the micro-credentials within their courses. They also recommended the pilot group identify a few credentials to start, which would serve as a foundation-building process. Early adopters could serve as ambassadors for change and the eventual endorsement of more micro-credentials in the future.

\section{Introduction to Faculty}

A targeted group of ten elementary education (ElEd) faculty began to examine the 28 micro-credentials. These faculty members had previously worked with educational technology (EdTec) faculty on two additional projects. The first 
included a technology mentoring project where the ElEd faculty members paired with undergraduate educational technology students who supported the faculty member to learn about and integrate technology within the faculty member's instructional practices. ElEd faculty also participated in another pilot program sponsored by ISTE to incentivize technology adoption within teacher education. As part of this pilot, the faculty received memberships and access to ISTE resources. The Educational technology faculty member held regular meetings with the ElEd faculty to discuss technology use and adoption within their instructional practices. Micro-credentials were introduced at these regular meetings.

Through the different professional development activities with ElEd faculty, it became evident that several of the faculty were utilizing technologies within their instructional practices and were requiring teacher education candidates to use technology in various assignments. However, the technology use was uneven, and candidate technology use was frequently dependent on a particular instructor. Microcredentials and their use within education were introduced to this group by an EdTec faculty member as part of their regular meetings about technology use and integration. $\mathrm{He}$ informed the faculty members about how micro-credentials could serve as a solution for documenting how candidates used and met various competencies with technology across their program. He also proposed the Digital Fliers program as a more uniform approach to document how candidate technology use is aligned with standards and embedded within existing courses. The created credential requirements included elements of existing assignments. The intention here was to demonstrate that adopting the micro-credentials could be an incremental shift for faculty instead of a new additional requirement or a complete overhaul of their existing practices. Demonstration of the credential requirements to faculty showed them how micro-credentials could modify similar but more traditional assignments.

Initial feedback about the micro-credentials was positive. ElEd faculty expressed interest in how they might develop micro-credentials themselves to assess candidates. They were also interested in how the micro-credentials could be used as a portfolio by candidates to share with potential employers and demonstrate their knowledge and skills. In additional conversations with the EdTec faculty member, ElEd faculty mapped where the different Digital Fliers micro-credentials might fit, if adopted, at various points throughout a candidate's program of study. Although the ElEd faculty supported introducing micro-credentials, they were concerned candidates, and other ElEd faculty may be overwhelmed if all 28 of the micro-credentials were adopted at once. By the middle of the spring 2020 semester, ElEd faculty had examined the credentials within the Digital Fliers program and agreed to pilot the use of two micro-credentials for the next semester within a single course.

\section{Introduction to Program Leadership}

The third group of stakeholders included EPP leadership. Providing evidence to demonstrate candidate preparation to use technology to support PK12 student learning was an area of concern for leadership. The EPP does not have a required educational technology course that could demonstrate a baseline of preparation for candidates. While student evidence and products from educational technology courses would provide needed evidence, the courses are electives. Documentation from those students of their technology use makes up only a small percentage of the overall candidate population. Additional evidence throughout the EPP would be inconsistent and not uniform for all candidates. To address this challenge, college leadership convened a technology subcommittee of five program areas and educational technology faculty to look for ways the EPP could demonstrate candidate preparation to use technology to support K12 student learning.

During the initial meetings of the technology subcommittee, the EdTec faculty member introduced the work he and his students had been doing on micro-credentialing. This meeting introduced micro-credentialing as a way to embed technology use throughout the EPP and provide a way for the EPP to easily report candidate performance for accreditation. Over the next several meetings, subcommittee members explored the Digital Fliers program and the various ways to report data using the Badge List platform. Similar to the ElEd faculty group, the subcommittee members considered how to adopt the micro-credentials throughout the EPP. Specifically, within which courses might one, two, or more micro-credentials support existing common key assessments or be modified in ways to replace existing assessments. The goal was to have each of the seven ISTE standards for educators addressed at different stages within a candidate's program of study. The sub-committee would eventually report and make recommendations to the university professional education committee.

The subcommittee believed that micro-credential adoption would be a way to address accreditation challenges and was in the process of recommending 3-4 areas across the EPP to include the micro-credentialing system. However, program leadership and accreditation personnel were concerned that adopting micro-credentials would raise concerns among education program faculty. Program faculty have various degrees of technology knowledge, and there were concerns that faculty would reject the adoption of the microcredential program without significant support.

Initial feedback for the Digital Fliers PLP had been positive by students and faculty. These initial steps toward piloting and developing the program abruptly halted during spring 2020 with the onset of the COVID-19 pandemic. Disruptions due to campus closures and transition to distance and remote learning made it difficult to continue the professional development and conversations about 
micro-credential adoption. The process renewed in Fall 2020.

Fall 2020 began with a variety of disruptions and concerns about safety. The semester also began with a broad realization among program faculty and leadership that candidates need to be prepared to use technology within their instructional practices. With new realities of remote and distance teaching and the need for candidates to demonstrate their competencies with technology, prospects for adopting micro-credentials gained support once again. The college had also gone through a change in leadership at both the Dean and Associate Dean positions. The new leadership was again seeking ways to address the EPP's challenges regarding candidates' preparation to use technology. At this same time, the university released a new strategic plan highlighting micro-credentials as a method to "accelerate career fulfillment and enhance personal development and well-being" (Ball State University, 2019, p.8). This renewed energy around the use of micro-credentialing at both the institutional and college levels has created the potential for implementing the Digital Fliers program.

\section{Lessons Learned from the Development and Introduction of Digital Fliers to Stakeholders}

Initial development of the Digital Fliers PLP is encouraging, and initial feedback is promising. However, programs need to do more to ensure teacher candidates successfully integrate technology into their future classrooms. Throughout the development and introduction of the Digital Fliers PLP, it became evident that additional work is needed and that adoption of the program within the EPP will take time. Feedback and suggestions about the micro-credentials highlighted challenges with faculty adopting a new system within the EPP to collect and assess evidence of candidate technology use. All three groups introduced to the program expressed concerns about faculty adoption even though designers intended to match existing course assessments and make incremental changes in what faculty might assign to their students.

Another common suggestion was that adoption of the micro-credentials should take place incrementally instead of adopting them all at once. This approach would allow a cohort of early adopters to support other faculty in integrating the micro-credentials. These suggestions from stakeholders align with literature related to educational change theory and considerations raised about the implementation of badge programs in higher education (Carey \& Stefaniak, 2018). Specifically, change is a complex process that takes time and involves various elements that can help or hinder the adoption of innovations (Fullan, 2007; Hall \& Hord, 2015; Rogers, 2003). The initial feedback from stakeholders continues to be used to develop the Digital Fliers program and work toward adopting the micro-credentials throughout the EPP.

\section{Conclusion}

The development of micro-credentials within EPP's can create opportunities for candidates to demonstrate a variety of knowledge, skills, and competencies and allow the programs to document how candidates use technology throughout the program. Change agents advocating for the creation and adoption of micro-credentials within educator preparation need to understand the organizational structure and context of the EPP. They also need to recognize change will be a process that may be slow at first but can build over time. Additional recognition that structural supports are essential to ensure successful implementation. These include

- support and recognition from program leadership indicating that technology use is an expected element that should be evident throughout the EPP;

- support and professional development for faculty; and

- support for candidates who may need additional skills to complete credentials and share their accomplishments with others.

Program leadership plays a key role in how programs advocate for, recognize, and incentivize faculty to help them prioritize technology use as something important to educator preparation (Clausen, 2020; Hall \& Hord, 2015; Kolb et al., 2018). Professional development for faculty can help them overcome their concerns about the adoption of micro-credentials. Some professional development options include traditional workshops, providing additional staff to assist faculty in embedding the credentials within courses, or technology mentoring where faculty work with undergraduate or graduate students to support faculty members' technology knowledge development. Additional support may also be needed to assist candidates in developing their portfolios of micro-credentials to be shared with faculty and future employers. Program leadership can aid these efforts by creating centers devoted to technology integration and infusion and staffed by personnel to assist faculty and candidates needing assistance.

Micro-credentialing can be an exciting aspect of larger efforts to infuse technology throughout the EPP, including educational technology coursework and structural supports for technology integration and infusion. For preparation programs that do not have a required educational technology course for all candidates, adopting and implementing a micro-credentialing system throughout the EPP may serve many purposes. These include 
- demonstration of how technology use is an expected and integral element of teaching and learning;

- a systematic documentation of candidates' technology use throughout their teacher education program;

- opportunities for the EPP to collect and report data on candidate's technology use for accreditation;

- opportunities for faculty to reconsider how candidates use technology in support of course goals and objectives; and

- how candidates develop and disseminate their professional competencies as they enter the workforce.

Adopting a micro-credentialing program does not mean that EPP's should eliminate their existing required educational technology courses. These courses continue to provide essential foundational knowledge for candidates about technology integration within instructional practices (Wilson et al., 2020). Instead, the adoption of micro-credentials can build on the foundation provided by required educational technology courses. From that foundation, micro-credentials can support preparation programs in demonstrating how they infuse technology throughout the entire program and create program-deep and program-wide experiences with technology for their candidates.
Acknowledgments The author wishes to thank Ellen Robertson, Megan Niese, and student designers for their contribution to the development of this project.

\section{Declarations}

Research Involving Human Participants The submitted manuscript is falls within TechTrends aims and scope under a report of innovative practice, report of a developmental program or trend, and discusses a matter of concern that might be of interest to practitioners. The information gathered is intended for the purposes of improving services and programs for students. The paper describes the design and iteration process of a project but is not a research study requiring human subjects approval.

Informed Consent The paper describes the design and iteration process. The paper reports lessons learned from that process. Designers of the project received informal feedback throughout the design process. No data was collected via formal interviews, surveys, or other methods.

Conflicts of Interest/Competing Interests The author has no financial or proprietary interests in any material discussed in this article.

Disclosure of Potential Conflicts of Interest The author has no conflicts of interest regarding the development and submission of this manuscript.

\section{Appendix}

\section{Digital Fliers Micro-credentials: ISTE Standards for Educators - Learner Standard}

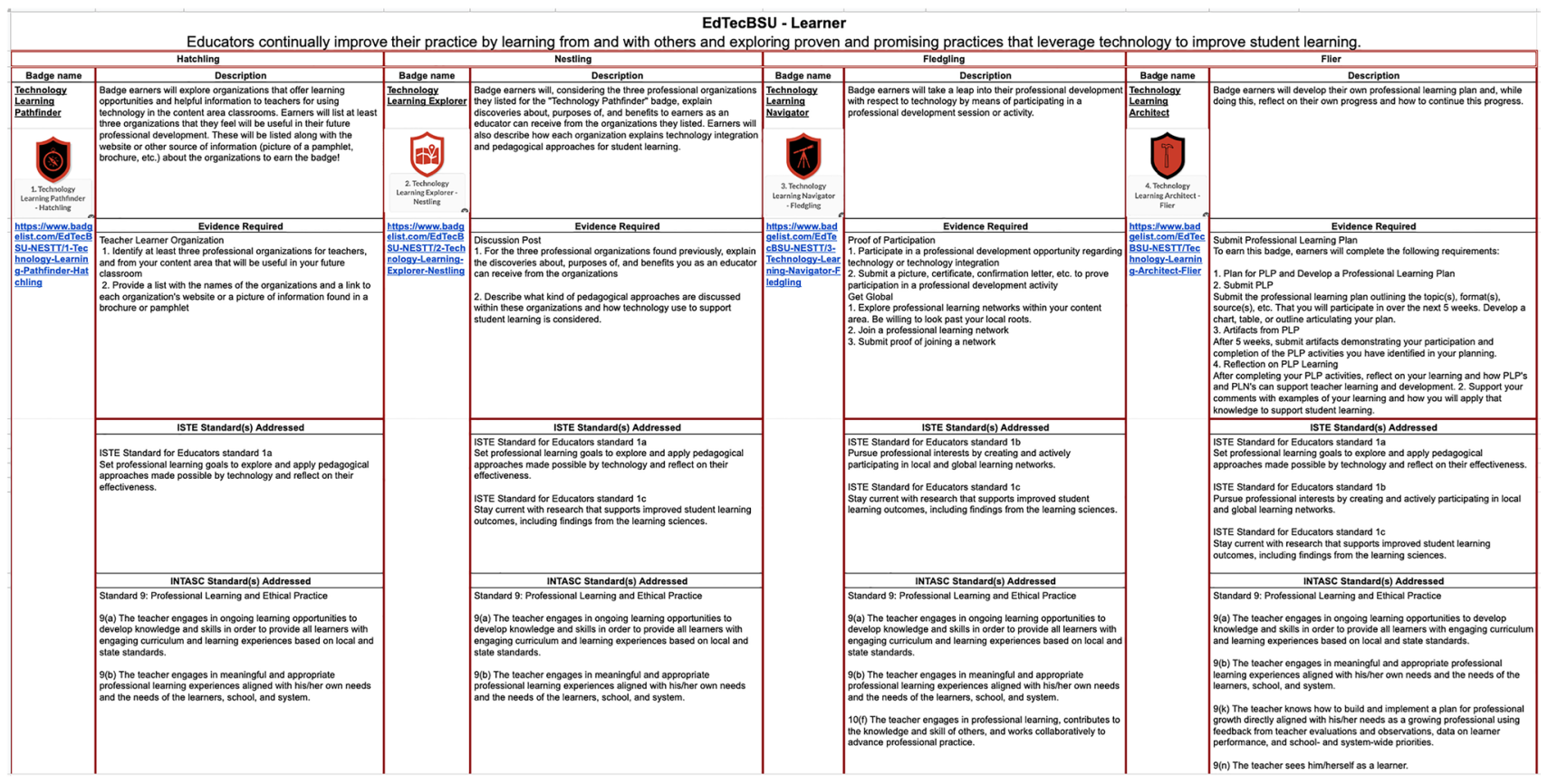




\section{References}

Ahn, J., Pellicone, A., \& Butler, B. S. (2014). Open badges for education: What are the implications at the intersection of open systems and badging? Research in Learning Technology. https://doi.org/ 10.3402/rlt.v22.23563

American Association of Critical-Care Nurses. (2020). COVID-19 micro-credential among first for clinical care. Retrieved from https://www.aacn.org/newsroom/covid-19-micro-credentialamong-first-for-clinical-care\#: :text=Micro\%2Dcredentials\% 2C\%20an\%20emerging\%20trend,specific $\% 20$ area\%20of\%20pro fessional\%20practice

Apple Teacher. (2020). Apple Teacher information. Retrieved from https://www.apple.com/education/k12/apple-teacher/

Badgr. (2020). The easiest way to issue digital badges and micro-credentials. Retrieved from https://info.badgr.com/

Ball State University. (2019). Destination 2040 our flight path: The 2019-24 strategic plan for Ball State University. Retrieved from https://www.bsu.edu/-/media/www/images/strategicplan/ball\% 20state\%20university\%20strategic\%20plan.pdf?la=en\&hash= DBA31978DD2AA3661FBA16C2DB2F7B026E65D548

Carey, K. L., \& Stefaniak, J. E. (2018). An exploration of the utility of digital badging in higher education settings. Education Technology Research and Development, 66, 1211-1229. https://doi.org/ 10.1007/s11423-018-9602-1

Cheng, Z., Watson, S. L., \& Newby, T. J. (2018). Goal setting and open digital badges in higher education. Tech Trends, 62, 190-196. https://doi.org/10.1007/s11528-018-0249-x

Clausen, J.M. (2020). Leadership for technology infusion: Guiding change and sustaining progress in teacher preparation. In A. C. Borthwick, T. S. Foulger, \& K. J. Graziano (Eds.), Championing technology infusion in teacher preparation: A Framework for supporting future educators (pp. 171-189). Portland, OR: International Society for Technology in Education.

Clausen, J.M., Borthwick, A. \& Rutledge, D. (2021). Teacher educator perspectives on technology infusion: A closer look using Q methodology. Journal of Technology and Teacher Education, 29(1), 5-43. Retrieved from https://www.learntechlib.org/prima $\mathrm{ry} / \mathrm{p} / 218585 /$.

Construction Management Association of America. (2021). CCM Digital Badging. Retrieved from https://www.cmaanet.org/ccm-digit al-badging

Council for the Accreditation of Educator Preparation. (2016). CAEP standards for initial-licensure programs. Retrieved from http:// caepnet.org/

Council for the Accreditation of Educator Preparation. (2021). 2022 CAEP Standards Introduction. Retrieved from http://caepnet.org/ standards/2022/introduction

Council of Chief State School Officers. (2011). Interstate teacher assessment and support consortium (InTASC) model core teaching standards: A resource for state dialogue. Retrieved from https:// ccsso.org/sites/default/files/2017-11/InTASC_Model_Core_Teach ing_Standards_2011.pdf

Devedzic, V., \& Jovanovic, J. (2015). Developing open badges: A comprehensive approach. Education Technology Research and Development, 63, 603-620. https://doi.org/10.1007/ s11423-015-9388-3

Digital Promise. (n.d.). Educator Micro Credentials. Retrieved from https://digitalpromise.org/initiative/educator-micro-credentials/

Elliott, R., Clayton, J., \& Iwata, J. (2014). Exploring the use of microcredentialing and digital badges in learning environments to encourage motivation to learn and achieve. In B. Hegarty, J. McDonald, \& S.-K. Loke (Eds.), Rhetoric and reality: Critical perspectives on educational technology. Proceedings ascilite Dunedin 2014 (pp. 703-707).
Foulger, T. S., Graziano, K. J., Schmidt-Crawford, D. A., \& Slykhuis, D. A. (2017). Teacher educator technology competencies. Journal of Technology and Teacher Education, 25(4), 413-448 Retrieved from https://www.learntechlib.org/p/181966/

Fullan, M. (2007). The new meaning of educational change (4th ed.). Teachers College Press.

Gamrat, C., Zimmerman, H. T., Dudek, J., \& Peck, K. (2014). Personalized workplace learning: An exploratory study on digital badging within a teacher professional development program. British Journal of Educational Technology, 45(6), 1136-1148.

Gibson, D., Ostashewski, N., Flintof, K., Grant, S., \& Knight, E. (2015). Digital badges in education. Education and Information Technologies, 20, 403-410. https://doi.org/10.1007/ s10639-013-9291-7

Gibson, D., Coleman, K., \& Irving, L. (2016). Learning journeys in higher. Designing Digital Pathways Badges for Learning, Motivation and Assessment. https://doi.org/10.5772/INTECHOPEN. 81380

Guathier, T. (2020). The value of microcredentials: The employer's perspective. The Journal of Competency-Based Education, 5(2), e01209.

Hall, G. E., \& Hord, S. M. (2015). Implementing change: Patterns, principles, and potholes. Upper Saddle River.

IBM. (n.d.) IBM credentials: Badges and Certifications. Retrieved from https://www.ibm.com/training/credentials

International Society for Technology in Education. (2017). Educational technology standards for educators. Retrieved from https://www. iste.org/standards/for-educators\#startstandards

Kolb, L., Kashef, F., Roberts, C., Terry, C., \& Borthwick, A. (2018). Challenges to creating and sustaining effective technology integration in teacher education programs. Retrieved from https://tech. ed.gov/edtechtprep/

Badge List. (2020). Digital badges help learning communities grow, engage, and inspire. Retrieved from https://www.badgelist.com/

Morris, B.J., Dragovich, C., Todaro, R., Balci,S., \& Dalton, E. (2019). Comparing badges and learning goals in low- and high-stakes learning contexts. Journal of Computing in Higher Education, 31 573-603. https://doi.org/10.1007/s12528-019-09228-9

Mozilla Foundation \& Peer 2 Peer University. (2012). Open badges for lifelong learning: Exploring an open badge eco-system to support skill development and lifelong learning for real results such as jobs and advancement. Working document. Retrieved from https://wiki.mozilla.org/images/b/b1/OpenBadges-Worki ng-Paper_092011.pdf

Newby, T. J., \& Cheng, Z. (2020). Instructional digital badges: Effective learning tools. Education Technology Research and Development, 68, 1053-1067. https://doi.org/10.1007/s11423-019-09719-7

Newby, T., Wright, C., Besser, E., \& Beese, E. (2016). Passport to designing, developing and issuing digital instructional badges. In Foundation of digital badges and micro-credentials (pp. 179201). Springer International Publishing.

Open Badges. (2020). What are open badges? Retrieved from https:// openbadges.org/

Organization for Economic Co-operation and Development. (2019). TALIS 2018 results (Volume I): Teachers and school leaders as lifelong learners. OECD Publishing. Retrieved from https://doi. org/10.1787/1d0bc92a-en

Randall, D. L., Harrison, J. B., \& West, R. E. (2013). Giving credit where credit is due Designing open badges for a technology integration course. TechTrends, 57(6), 88-95. https://doi.org/10.1007/ s11528-013-0706-5

Reid, A. J., Paster, D., \& Abramovich, S. (2015). Digital badges in undergraduate composition courses: Effects on intrinsic motivation. Journal of Computers in Education, 2(4), 377-398.

Rogers, E. M. (2003). Diffusion of innovations. Free Press. 
Skipper, W. (2018). Introducing Badgr Pathways. Concentric Sky. Retrieved from https://www.concentricsky.com/articles/detail/ introducing-badgr-pathways

Stefaniak, S., \& Carey, K. (2019). Instilling purpose and value in the implementation of digital badges in higher education. International Journal of Educational Technology in Higher Education, 16(44). https://doi.org/10.1186/s41239-019-0175-9

U.S. Department of Education, Office of Educational Technology (2016). Advancing educational technology in teacher preparation: Policy brief. Retrieved from https://tech.ed.gov/files/2016/ 12/Ed-Tech-in-Teacher-Preparation-Brief.pdf

U.S. Department of Education, Office of Educational Technology (2017). Reimagining the role of technology in education: 2017 national education technology plan update. Retrieved from https://tech.ed.gov/files/2017/01/NETP17.pdf

Watson, S. L., Yu, J. H., Alamri, H., \& Watson, W. R. (2020). Pre-service teachers' technology integration attitude change in a course implementing digital badges. Journal of Technology and Teacher Education, 28(1), 89-116 Retrieved from https://www.learntechl ib.org/primary/p/211054/

West, R. E., \& Randall, D. L. (2016). The case for rigor in open badges. In L. Y. Muilenburg \& Z. L. Berge (Eds.), Digital badges in education: Trends, issues, and cases. New York, NY.
West, R. E., Tawfik, A. A., Gishbaugher, J. J., \& Gatewood, J. (2020). Guardrails to constructing learning: The potential of open microcredentials to support inquiry-based learning. TechTrends, 64, 828-838. https://doi.org/10.1007/s11528-020-00531-2

Wilson, B. G., Gasell, C., Ozyer, A., \& Scrogan, L. (2016). Adopting digital badges in higher education: Scoping the territory. In D. Ifenthaler, N. Bellin-Mularski, \& D.-K. Mah (Eds.), Foundation of digital badges and micro-credentials (pp. 163-177). Springer.

Wilson, M. L., Ritzhaupt, A. D., \& Cheng, L. (2020). The impact of teacher education course for technology integration on preservice teacher knowledge: A meta-analysis study. Computers in Education, 156. https://doi.org/10.1016/j.compedu.2020.103941

Young, D., West, R. E., \& Nylin, T. A. (2019). Value of microcredentials to earners and issuers: A case study of national instruments open badges. The International Review of Research in Open and Distance Learning, 20(5), 104-121.

Publisher's Note Springer Nature remains neutral with regard to jurisdictional claims in published maps and institutional affiliations. 